\title{
PENTECOSTAIS E MOVIMENTO LGBT NAS ELEIÇÕES PRESIDENCIAIS DE 2014
}

\author{
Janine Trevisan ${ }^{l}$
}

Resumo: $\mathrm{O}$ artigo realiza uma análise da presença pentecostal nas eleições presidenciais de 2014, especialmente no que se refere ao confronto estabelecido com o movimento LGBT. O artigo está dividido em duas partes. Na primeira, para compreender o processo que repercutiu em 2014, analiso as ações do governo Lula (2003-2010) e do primeiro governo Dilma (2011-2014) para atender as demandas tanto do segmento evangélico quanto do movimento LGBT, buscando destacar o processo político pelo qual lideranças evangélicas ganharam espaço e força política a ponto de confrontar demandas de movimentos sociais, especialmente feministas e LGBT. A segunda parte analisa o primeiro turno das eleições presidenciais de 2014, explorando o caso da controversa alteração no programa da candidata Marina Silva (PSB) sobre as políticas para o segmento LGBT. O caso foi emblemático para demonstrar o crescente embate político entre lideranças pentecostais e lideranças em defesa dos direitos LGBT no Brasil.

Palavras-chave: Pentecostais; Política; Eleições 2014; Movimento LGBT.

Abstract: The article presents an analysis of the Pentecostal presence in the presidential elections in 2014, especially with regard to the established confrontation with the LGBT movement. The article is divided into two parts. First, to understand the process that resonated in 2014, it analyzes the actions of the Lula government (2003-2010) and the first Dilma government (2011-2014) to meet the demands of both the evangelical segment as the LGBT movement, seeking out the political process whereby evangelical leaders gained enough political power to confront demands of social movements, especially feminist and LGBT. The second part analyzes the first round of the 2014 presidential elections, exploring the case of

\footnotetext{
1 Doutoranda em Ciências Sociais - Programa de Pós-Graduação em Ciências Sociais da Pontifícia Universidade Católica do Rio Grande do Sul. Contato: janinebt@uol.com.br Agradeço à CAPES pela bolsa concedida, que possibilitou a realização da pesquisa para este artigo.
}

Debates do NER, Porto Alegre, ano I6, N. 27, P. 289-32I, JAn./Jun. 2015 
controversial changes to the program of the candidate Marina Silva (PSB) on policies for the LGBT segment. The case was emblematic to demonstrate the growing political struggle between Pentecostal leaders and those in defense of LGBT rights in Brazil.

Keywords: Pentecostals; Politics; 2014 Elections; LGBT Movement.

\section{INTRODUÇÃO}

O pleito eleitoral presidencial de 2014 revelou o crescente embate político entre lideranças pentecostais e aquelas em defesa dos direitos LGBT no Brasil. Resultado de um processo deflagrado há pelo menos três décadas, no momento da redemocratização do país, quando ambos os movimentos despontaram no cenário político em defesa de seus interesses específicos, o confronto entre os dois grupos no cenário eleitoral de 2014 demonstrou o fracasso das tentativas de acomodação das demandas dos dois segmentos pelos governos desde então, bem como as consequências dessas investidas. Compartilho do entendimento de Vital e Lopez (2013) de que a circulação dos evangélicos pelos campos político e religioso empoderou suas lideranças que, sustentadas pelos discursos dos direitos e da democracia passaram a reivindicar um lugar legítimo no espaço público para legislar segundo seus valores cristãos. Nesse cenário, suas lutas confrontaram-se diretamente com as de outros movimentos sociais, em especial o feminista e o LGBT.

No presente artigo, discorro sobre o processo histórico que oportunizou a referida disputa para, em seguida, ilustrá-la com a problematização de um caso específico ocorrido no primeiro turno da campanha presidencial de $2014^{2}$.

2 A pesquisa fez parte da investigação de minha tese de doutorado e foi realizada durante o período de 2011 a 2014, envolvendo análise de notícias de imprensa, impressa e eletrônica, observaçōes sistemáticas de audiências e reuniōes no Congresso Nacional, sempre que envolviam questões que colocavam em disputa esses dois grupos de atores políticos: lideranças e parlamentares pentecostais, por um lado, e lideranças e parlamentares em defesa dos direitos civis feministas e LGBT, por outro. Além disso, foram realizadas 
Neste pleito, do total de onze candidatos, dois são membros da igreja pentecostal Assembleia de Deus. Uma dessas candidaturas, a do Pastor Everaldo (PSC), é oficialmente pentecostal, apoiada pelas principais lideranças pentecostais do país. Será, no entanto, sobre a outra que vou me debruçar neste texto. Trata-se da candidata Marina Silva que, em 2014, concorreu à presidência da república pelo Partido Socialista Brasileiro (PSB).

Diferentemente do que as gestões do presidente Luis Inácio Lula da Silva (2003-2010) tentaram e, em certa medida conseguiram realizar, no sentido de atender (ou acomodar) tanto as demandas do segmento pentecostal quanto as do segmento LGBT, o cenário eleitoral de 2014 demonstrou a dificuldade crescente de não se posicionar explicitamente em favor de um dos lados do embate. Afinal, o que parece mesmo estar em jogo, por trás dos discursos semânticos acerca da laicidade do estado brasileiro, é muito mais uma disputa pelo exercício estatal de um controle social, pelo lado dos pentecostais, e, do lado dos movimentos sociais, pelo direito de autonomia individual.

Para compreender esse processo que repercutiu em 2014, o artigo está dividido em duas partes. Na primeira, apresento uma rápida retrospectiva acerca da inserção pentecostal e LGBT no cenário político do Brasil redemocratizado, bem como discuto algumas das açôes do governo Lula (2003-2010) e do primeiro governo Dilma (2011-2014) que foram realizadas para atender (ou acomodar) as demandas tanto do segmento evangélico quanto do movimento LGBT, buscando destacar o processo político pelo qual lideranças evangélicas conquistaram espaço e força política a ponto de confrontar demandas de movimentos sociais, especialmente feministas e LGBT. A segunda parte analisa o embate entre lideranças pentecostais e movimento LGBT durante o primeiro turno das eleiçôes presidenciais de 2014, explorando o caso da controversa alteração no programa da candidata Marina Silva (PSB) sobre as políticas para o segmento LGBT.

entrevistas com parlamentares e seus assessores, tanto dos pentecostais quanto dos em defesa dos direitos civis de feministas e LGBTs.

Debates do NER, Porto Alegre, ano I6, N. 27, P. 289-32I, JAn./Jun. 2015 


\section{PENTECOSTAIS E LGBT NA ARENA POLÍTICA BRASILEIRA}

Desde 2010, temáticas e argumentos religiosos vêm ganhando destaque nas eleições presidenciais brasileiras. Tal ênfase resulta especialmente da crescente participação pentecostal na política nacional. Juntamente com sua expansão demográfica exponencialmente acelerada desde a década de 1980 (Mariano, 2000), os pentecostais ingressam na política em defesa dos seus interesses religiosos e da manutenção da moral cristã e dos bons costumes.

Diversos autores (Freston, 1993; Pierucci, 1996; Mariano, 2009; Baptista, 2009) já demonstraram a radical mudança de perfil desse segmento no que se refere ao seu ativismo político desde a redemocratização do país na década de 1980. As eleições para deputados federais constituintes, em 1986, foram as primeiras a eleger um número considerável de parlamentares pentecostais, 18, dentre 32 evangélicos eleitos (Pierucci, 1996). Logo a imprensa noticiou a formação e atuação da bancada evangélica. Durante a escritura da nova Carta Magna, realizaram diversas alianças e assumiram majoritariamente posição à direita no espectro ideológico.

O movimento LGBT, embora focado no combate à epidemia da AIDS durante as décadas de 1980 e 1990, pressionou os parlamentares constituintes de 1988 pela inclusão da orientação sexual dentre as condições para proteção contra discriminação na nova Constituição. A demanda, no entanto, foi rejeitada, sobretudo em razão dos argumentos dos conservadores opositores dos direitos das minorias sexuais (Marsiaj, 2006), muitos deles evangélicos que se mostraram, em sua maioria, ferrenhos adversários daqueles que buscavam avanços constitucionais na área dos direitos sexuais e reprodutivos. Como demonstrou Marsiaj (2006), os principais defensores dessa proposta eram os parlamentares dos partidos de esquerda. Deputados dos partidos de centro e de direita que votaram a favor dessa demanda representavam casos isolados. Além disso, a grande maioria dos evangélicos, que defendiam a manutenção da família tradicional e, portanto, contra todos os direitos do 
movimento LGBT, estavam ancorados nos partidos de centro e direita ${ }^{3}$. Por conta desse confronto, marca-se o momento da Assembleia Nacional Constituinte, que culminou com a promulgação da nova Constituição Federal em 1988 como um espaço inicial da disputa que iria se acirrar anos mais tarde entre pentecostais, por um lado, e movimento LGBT (e feministas também), por outro.

A partir de meados da década de 1990, o movimento LGBT que, em grande medida, encontrou espaço de acolhida sobretudo no Partido dos Trabalhadores (PT), conseguiu ampliar suas reivindicações para outros direitos civis indo além do combate à epidemia da AIDS, como a união homoafetiva e a criminalização da homofobia. Em 1995, é criada a Associação Brasileira de Gays, Lésbicas, Travestis e Transexuais (ABGLT). Nesse mesmo período, começaram a surgir projetos de lei visando à ampliação dos direitos civis desse segmento social, apresentados especialmente por parlamentares de partidos de esquerda, como a deputada Marta Suplicy, do Partido dos Trabalhadores. É de sua autoria o projeto de 1995 para o reconhecimento da união civil homoafetiva, bem como da emenda constitucional para incluir orientação sexual nos artigos 3, que trata da "promoção do bem de todos, sem preconceitos de origem, raça, cor idade e quaisquer outras formas de discriminação", e 7, que trata "da proibição de diferença salarial, de exercício de funções e de critérios de admissão por motivos de sexo, idade, cor ou estado civil”, da Constituição Federal, no mesmo ano. Desde então, dezenas de projetos tramitam na Câmara dos Deputados envolvendo demandas por direitos da população LGBT.

$\mathrm{O}$ ano de 2002 foi marcado politicamente pela eleição do candidato do Partido dos Trabalhadores à presidência da república, Luiz Inácio Lula da Silva. Com a vitória petista, lideranças dos movimentos sociais pelos

3 Importante salientar a ocorrência de defensores dos direitos LGBT também nos partidos de centro e direita, assim como de parlamentares pentecostais nos partidos de esquerda, revelando a não homogeneidade dos grupos nas duas situaçóes descritas.

Debates do NER, Porto Alegre, ano I6, N. 27, P. 289-32I, JAn./Jun. 2015 
direitos humanos, feministas e LGBT alimentaram expectativas de finalmente conquistar uma série de direitos, na medida em que o principal partido que os representa politicamente alcançou o poder.

Para garantir a eleição, no entanto, o PT ampliou suas alianças e recebeu apoio político de algumas lideranças pentecostais importantes. Depois de três campanhas em que Lula era rechaçado, tanto pelas lideranças como pela comunidade pentecostal, como a encarnação do demônio, como aquele que limitaria a liberdade das igrejas evangélicas e privilegiaria a Igreja Católica, o petista finalmente reverte tal perspectiva no segundo turno da campanha presidencial de 2002. Além disso, cabe destacar também as alianças realizadas com partidos de centro e direita no espectro ideológico, que apoiaram Lula e com ele compuseram o governo eleito em 2002. Com essa nova configuração política, a partir desse momento, o novo presidente empenhara-se para também acolher os evangélicos e assim desfazer qualquer imagem ameaçadora que tal segmento da população pudesse ainda nutrir contra ele.

Em razão de interesses conflitantes, uma disputa até então pouco visível entre movimentos sociais (em especial o LGBT) e lideranças pentecostais se acirra. No cenário de uma campanha presidencial, no entanto, é somente em 2010 que tal confronto recebe maior visibilidade e é no pleito de 2014 que as lideranças LGBT e pentecostais são confrontadas de modo que, ainda que os candidatos tentem acomodar ${ }^{4}$ os dois lados, tal tarefa mostra-se problemática.

Ainda que as reivindicaçôes dos movimentos sociais de minorias como o movimento LBGT e o movimento feminista não fossem prioridade dentro

4 Lori Beaman, em sua obra Reasonable Accommodation (2011), demonstra como a ideia de acomodação razoável emergiu como uma das formas nas quais a negociação é enquadrada no modelo multicultural canadense, tendo inicialmente sido acionada como um mecanismo para atender demandas por flexibilidades no ambiente de trabalho e educacional, em razão de práticas religiosas específicas. No entanto, foi logo ampliada para outras esferas e grupos sociais, como no caso das minorias sexuais demonstrado por Shipley (2011).

Debates do NER, Porto Alegre, Ano i6, N. 27, P. 289-32I, JAN./Jun. 2015 
do Partido dos Trabalhadores, sendo vistos como secundários por muitos petistas, era nesse partido que tais movimentos tinham, de alguma forma, suas demandas acolhidas e suas lutas representadas no campo político partidário. A aliança com o segmento evangélico trouxe um dilema ainda maior para o interior do partido, que viria a ser explicitamente notado somente anos mais tarde. Fato é que ao tentar atender demandas de segmentos tão diversos, o governo Lula fortalecia de certa forma ambos os lados para a disputa que iria se acirrar logo adiante.

O empenho do governo Lula em aproximar-se dos evangélicos culminou com a alteração no Código Civil, sancionado por Lula no final de 2003, que garantiu personalidade jurídica própria às igrejas e entidades religiosas, bem como a inserção de evangélicos em conselhos de políticas públicas (Mariano, 2006). A cerimônia de sanção dessa lei foi acompanhada por cerca de 150 lideranças religiosas e, em seu discurso ${ }^{5}$, Lula declarou, conversando diretamente com os religiosos que estavam na plateia:

Durante muitos e muitos anos eu encontrava com pastores, pelo Brasil afora, que me perguntavam: 'Lula, é verdade que, se você ganhar as eleições, vai fechar as igrejas evangélicas'? Vocês sabem disso. E quis Deus que, no primeiro ano do meu governo, a última lei que sanciono, no ano de 2003, é exatamente para dizer que aqueles que me difamaram agora vão ter que pedir desculpas, não a mim, mas a Deus e à sua própria consciência.

Em meio a gritos de "Glória a Deus", o presidente Lula foi aplaudido e ainda recorreu ao ditado popular "Deus escreve certo por linhas tortas", para argumentar que a última lei do ano, sancionada por ele, garantia a liberdade religiosa no Brasil.

Com relação às demandas do movimento LGBT, em 2004, o governo Lula lança o programa Brasil sem Homofobia, como a primeira de uma série de medidas que irão permitir ao segmento avançar na conquista de algumas

5 Disponível em: <http://www1.folha.uol.com.br/folha/brasil/ult96u56689.shtml>. Acesso em: 23 maio 2014 .

Debates do NER, Porto Alegre, ano I6, N. 27, P. 289-32I, JAn./Jun. 2015 
de suas reivindicações. Desde a posse de Lula, em 2003, diversas outras mobilizaçôes, organizadas por lideranças do movimento LGBT, levantaram a bandeira contra a homofobia e pelos direitos civis do segmento. Alguns exemplos das temáticas das paradas em São Paulo incluem: Construindo Politicas Homossexuais (2003); Temos Familia e Orgulho (2004); Parceria civil, já. Direitos iguais! Nem mais nem menos (2005); Homofobia é Crime! Direitos Sexuais são Direitos Humanos (2006); Por um mundo sem Racismo, Machismo e Homofobia (2007); Homofobia Mata! Por um Estado Laico de Fato (2008); Sem Homofobia, Mais Cidadania - Pela Isonomia dos Direitos! (2009); Vote Contra a Homofobia: Defenda a Cidadania! (2010); Amai-vos uns aos outros: basta de homofobia! (2011); Homofobia tem cura: educação e criminalização (2012); Para o armário nunca mais: União e conscientização na luta contra a homofobia (2013); Pais vencedor é pais sem homolesbostransfobia: chega de mortes! criminalização já! (2014). Tais bandeiras, levantadas na maior mobilização LGBT do Brasil, deram o tom para diversas outras manifestações nas principais cidades do país.

Segundo Machado (2012, p. 33), as duas últimas décadas foram marcadas por transformações culturais que resultaram em uma política de aproximação do Estado brasileiro com os movimentos sociais que buscavam reconhecimento na sociedade:

Nesse período, enquanto as feministas eram chamadas a ocuparem postos no aparelho do Estado, influenciando as políticas na área da saúde e dos direitos sexuais e reprodutivos, os segmentos de gays e lésbicas se constituíram como importantes atores políticos coletivos, obrigando a sociedade a debater temas polêmicos, como: a descriminalização do aborto; a união civil entre pessoas do mesmo sexo; a adoção de crianças por casais homoafetivos; a criminalização da homofobia; a inclusão das cirurgias de readequação sexual entre os Serviços do Sistema único de Saúde; etc. Ainda que de forma desigual, esses movimentos (o feminista e o LGBTT) viram muitas de suas propostas serem encaminhadas nos governos do PSDB (1995-1998 e 1999-2002) e, mais acentuadamente, nos dois mandatos do petista Luís Inácio Lula da Silva (2003-2006 e 2007-2010) (Machado, 2012b, p. 33). 
Destaque-se ainda, nesse cenário, a instalação da Comissão Tripartite de Revisão da Legislação Punitiva sobre o Aborto, em 2005; a 1a Conferência Nacional LGBT, em 2008, e o lançamento do III Programa Nacional de Direitos Humanos (PNDH3) ${ }^{6}$, em 2009.

Em um dos trechos mais polêmicos do PNDH3, a recomendação para a desconstrução da heteronormatividade abre caminhos para muitas das conquistas do movimento LGBT, gerando revolta entre as lideranças pentecostais que alertam, a partir dessa recomendação, para o perigo que a família brasileira estaria correndo.

Considerando as campanhas eleitorais para presidente da república, foi somente no pleito presidencial de 2010 que os apoios negociados desde 2002, as ações decorrentes desses acordos e os avanços que os movimentos ligados aos direitos humanos e às minorias, especialmente dos movimentos feminista e LGBT, conquistados durante dois mandatos do governo Lula, suscitaram uma reação religiosa que conclamou o posicionamento explícito dos principais candidatos. A afirmação de 1997 do cientista político Joanildo Burity parecia mais do que adequada:

[...] os partidos e candidatos que não levam em consideração os grupos religiosos em seu discurso e estratégia correm sério risco de se complicarem ou inviabilizarem eleitoralmente. (Burity, 1997, p. 161-162)

Além disso, outros acontecimentos contribuíram para esse espaço que a religião ocupou no cenário eleitoral, entre os quais as declaraçóes anteriores da candidata petista Dilma Rousseff acerca de seu posicionamento sobre o

6 O III Plano Nacional de Direitos Humanos (PNDH3) foi lançado pelo presidente Lula em dezembro de 2009. Apresentado como um roteiro com seis eixos e 25 diretrizes, causou polêmica entre católicos e evangélicos, especialmente pelas questôes relacionadas às políticas para a população LGBT, feministas, profissionais do sexo ali propostas.

7 Conforme objetivo estratégico V do PNDH3. Disponível em: <http://www.sdh.gov.br/ assuntos/direito-para-todos/programas/pdfs/programa-nacional-de-direitos-humanospndh-3>. Acesso em: 18 dez. 2011.

Debates do NER, Porto Alegre, ano I6, N. 27, P. 289-32I, JAn./Jun. 2015 
aborto enquanto questão de saúde pública ${ }^{8}$ e as polêmicas no interior do Congresso Nacional sobre o aborto a partir da resolução do $3^{\circ}$ Congresso Nacional do PT?

A maneira como os segmentos religiosos pautaram o pleito presidencial de 2010 mereceu a atenção de diversos pesquisadores da área. Oro e Mariano (2010) demonstram a instrumentalização mútua entre religião e política e a forma como as lideranças religiosas impuseram o comprometimento com suas pautas em troca de apoio político eleitoral. Pierucci $(2011$, p. 5) afirma não lembrar de uma campanha eleitoral em que a "[...] intromissão da religião tenha sido tão grande e tenha ido tão longe como na eleição presidencial para a sucessão de Lula". Machado (2012a) analisou o ativismo religioso (evangélico e católico) e a inclusão do tema do aborto nessas eleiçôes, demonstrando o caráter reativo do que chamou de ativismo religioso conservador em relação aos avanços dos movimentos no campo feminista e da diversidade sexual no país. Em outro artigo do mesmo ano, Machado (2012b), ao analisar o ativismo religioso conservador nas eleições de 2010 a partir dos embates entre católicos, evangélicos e os movimentos feminista e LGBT na esfera pública brasileira, aponta que a despeito dos conflitos de interesses entre os atores católicos e evangélicos, parcerias vêm sendo desenvolvidas entre coletivos religiosos de ambos os lados com o objetivo de impedir a criação de uma moralidade sexual de caráter laico. (Machado, 2012b, p. 56)

Cabe destacar que no momento em que a pauta dos temas religiosos, especialmente do aborto, mas também da criminalização da homofobia e do casamento homoafetivo, vieram à tona e ameaçaram a eleição da candi-

8 Em entrevista ao jornal Folha de São Paulo em 2007 e à revista Marie Claire em 2009, Dilma Rousseff defendeu o tratamento do aborto enquanto problema de saúde pública. Disponível em: <http://www1.folha.uol.com.br/folha/videocasts/ult10038u333958. shtml>; <http://revistamarieclaire.globo.com/Revista/Common/0,EMI175873-177353,00-A+MULHER+DO+PRESIDENTE+CONFIRA+A+ENTREVISTA+QUE+ DILMA+ROUSSEFF+CONCEDEU+A+M.html>. Acesso em: 25 jun. 2012.

9 Disponível em: <https://www.pt.org.br/wp-content/uploads/2014/03/Resolucoesdo3o CongressoPT.pdf>. Acesso em: 15 abr. 2014.

Debates do NER, Porto Alegre, Ano i6, N. 27, P. 289-32I, JAN./Jun. 2015 
data Dilma Rousseff em 2010, que diversas lideranças religiosas e políticas saíram em sua defesa em troca do seu comprometimento para não avançar ainda mais, no caso de eleita, nas conquistas dos direitos reclamados pelos grupos feministas e LGBT.

Assim, Dilma recuou com relação aos seus posicionamentos anteriormente publicizados. No final da campanha para o $1^{\circ}$ turno, a candidata petista reuniu lideranças católicas e evangélicas para desmentir boatos, reafirmar seu posicionamento contra o aborto e seu compromisso em não tomar iniciativas para alterar a legislação tanto no caso do aborto como no caso da união civil entre homossexuais. Garantiu que deixaria tal tarefa para o Congresso Nacional. Na ocasião, Dilma pregou parceria com as igrejas e as destacou enquanto entidades importantes para ajudar na erradicação da pobreza e no combate às drogas, além de defender que presidente não deve ter religião, mas respeitar a todas, pregando, dessa forma, a liberdade de crença (Oro; Mariano, 2010).

Já no segundo turno, Dilma teve de enfrentar as demandas dos evangélicos que acenavam com seu apoio explícito caso ela se comprometesse com suas exigências ou, na linguagem de uma assessora ${ }^{10}$ entrevistada, que ela "assinasse sua fatura":

Então a liderança evangélica se reuniu e uma figura que teve papel importante nesse processo foi o Magno Malta e o Rodovalho. E eles sentaram com o PT e disseram: 'Vocês aceitam a nossa fatura, nós temos uma fatura a apresentar', e eles apresentaram a fatura, que era não vir nada do executivo com relação ao aborto, a questão da homofobia ser discutida com a devida atenção e a Dilma assinou aquela carta, né? Então a carta a gente tem, esta aí. A partir desse momento a liderança evangélica se sentiu à vontade para apoiar Dilma porque essa conversa eles não conseguiriam ter com Serra. Não conseguiriam, por mais que o Serra seja aparentemente conservador, o Serra naquele momento era uma incógnita, entendeu?

${ }^{10}$ Entrevista realizada com assessora de parlamentar evangélico, concedida em dezembro de 2012.

Debates do NER, Porto Alegre, ano I6, N. 27, P. 289-32I, JAn./Jun. 2015 
Tal "fatura" mencionada pela assessora entrevistada se refere ao compromisso assinado por Dilma com o documento que foi lançado em 15 de outubro de 2010, durante a campanha eleitoral como "Mensagem da Dilma", que continha os compromissos de defender a convivência entre as diferentes religiōes e a liberdade religiosa e de expressão; a manutenção da legislação sobre o aborto; a proteção à família e a revisão do PNDH3. ${ }^{11}$

A partir desse acordo, a nova presidenta eleita passou a ser cobrada e vigiada pelas lideranças evangélicas dentro e fora do Congresso Nacional. Internamente, a Frente Parlamentar Evangélica ${ }^{12}$, organizada institucionalmente desde 2003, e composta por 75 deputados federais e três senadores eleitos em $2010^{13}$, tratou de assumir a incumbência de controlar o cumprimento de tais compromissos firmados.

Durante o primeiro governo Dilma, diversos eventos colocaram o segmento evangélico em situação de cobrar da presidenta o cumprimento dos compromissos firmados no período eleitoral. A primeira situação aconteceu logo no início de 2011, quando o então Ministro da Educação, Fernando Haddad, lançou um material que ficou conhecido como kit anti homofobia

${ }^{11}$ Disponível em: <http://www1.folha.uol.com.br/fsp/poder/po1610201010.htm>. Acesso em: 19 jun. 2012.

${ }^{12}$ A Frente Parlamentar Evangélica, embora bastante heterogênea tanto no campo político (diferentes partidos) quanto no campo religioso (diferentes denominaçōes), tem mostrado forte capacidade de mobilização e atuação conjunta no que diz respeito aos projetos que envolvem temáticas comportamentais, especialmente naquilo que consideram como ameaça à família tradicional e aos bons costumes. Para uma análise mais detalhada da Frente Parlamentar Evangélica, ver Baptista (2009), Duarte (2011) e Trevisan (2013).

13 De acordo com dados coletados por Tadvald (2010) e Duarte (2011), o número de eleitos em 2010 foi de 75 deputados federais e três senadores, totalizando 78 parlamentares eleitos para a 54a legislatura. O DIAP (Departamento Intersindical de Assessoria Parlamentar divulgou, logo após as eleições, o número de 73 parlamentares evangélicos eleitos, sendo 70 deputados federais e três senadores. A dificuldade de se alcançar o número exato refere-se sobretudo à identificação da filiação religiosa dos eleitos, nem sempre evidente. Vale lembrar que esse número sofre alterações constantes, em razão de fatores diversos, como saída para exercer cargo no poder executivo e ingresso por suplência.

Debates do NER, Porto Alegre, Ano i6, N. 27, P. 289-32I, JAN./Jun. 2015 
ou, nas palavras de seus detratores kit gay. Tratava-se de um conjunto de vídeos e outros materiais didáticos a ser distribuído nas escolas públicas com o intuito de subsidiar os educadores para uma abordagem contra a discriminação por orientação sexual no ambiente escolar. As lideranças evangélicas logo entenderam o material como instrutivo no sentido de "ensinar a ser gay" e, portanto, apresentando riscos à família brasileira. Com o intuito de forçar o Ministro a retirar o material de circulação, parlamentares evangélicos, ameaçaram obstruir a votação de qualquer outro projeto no plenário da Câmara dos Deputados caso o kit não fosse retirado. A presidenta Dilma Rousseff cedeu à pressão, solicitando ao Ministro da Educação, Fernando Haddad, que retirasse o material, para melhor avaliação junto à sociedade, apesar das manifestações contrárias do movimento LGBT.

Em resposta a essa controvérsia, a maior parada LGBT do país, realizada em São Paulo, adotou naquele ano o tema Amai-vos uns aos outros: basta de homofobia. Em início de maio de 2011, o Supremo Tribunal Federal reconheceu a união civil homoafetiva, garantindo aos casais do mesmo sexo os mesmos direitos civis dos heterossexuais, gerando revolta entre os pentecostais.

Enquanto o confronto entre a comunidade LGBT e os pentecostais acirrava-se nas ruas, os primeiros lutando pela criminalização da homofobia e os últimos, mobilizando em favor da liberdade de expressão ${ }^{14}$, o governo Dilma, até pelo menos a metade do seu mandato, conseguiu contornar as situações que surgiram e cumprir com suas promessas aos evangélicos. Entrevista realizada com assessora da Frente Parlamentar Evangélica em dezembro de 2012 atesta o sentimento vigente:

\footnotetext{
${ }^{14}$ Em 18 de maio de 2011, a AGBLT realizou, em Brasília, a II Marcha Nacional contra a Homofobia pela aprovação imediata do PLC122. Duas semanas depois, em 01/06/2011, organizadores da Marcha da Família realizam a denominada Manifestação pacífica em favor da família, pela liberdade de expressão, liberdade religiosa e abaixo o PLC 122, também em Brasília, quando entregaram ao presidente do Senado um abaixo-assinado com mais de um milhão de assinatura contra o PLC 122.
}

Debates do NER, Porto Alegre, ano I6, N. 27, P. 289-32I, JAn./Jun. 2015 
Dilma nos surpreende, ela surpreende a Igreja Evangélica. Com relação à carta de princípios, ela tem cumprido com tudo. Nós não podemos reclamar de nada. Existe hoje admiração à Dilma, a bancada evangélica tem uma admiração e um respeito, toda vez que a gente vai para um embate que envolve a presidente Dilma a gente vai com respeito, nós questionamos mais o PT do que ela, acho que não dá para ver muito Dilma PT. ${ }^{15}$

Ainda que até o final de 2012 o governo Dilma tenha cedido às pressões dos evangélicos e recuado em muitas de suas proposições, provocando vergonha e constrangimento para muitos petistas saudosistas dos velhos tempos de oposição, o fato é que o ano de 2013 iniciou trazendo situações nas quais o silêncio da presidenta Dilma se tornou alvo de críticas contundentes por parte das lideranças pentecostais. Refiro-me ao caso emblemático da indicação do deputado Pastor Marco Feliciano (PSC/SP), aliado do governo, à presidência da Comissão de Direitos Humanos e Minorias da Câmara dos Deputados. Quando a sociedade civil ergueu-se contra Feliciano em protestos por todo o país, as lideranças evangélicas que o apoiavam lembraram que seu partido era aliado do governo e que Dilma deveria posicionar-se em sua defesa. O silêncio da presidenta, no entanto, acionou o início de uma série de situações a partir das quais esse grupo de lideranças evangélicas que a tinha apoiado em 2010 concluiu que ela estava rompendo com o anteriormente combinado. Leve-se ainda em conta a tramitação do PLC $122 / 2006^{16}$ no Senado Federal, defendido abertamente pela grande maioria dos parlamentares petistas ${ }^{17}$, que, após diversos embates, foi finalmente

${ }^{15}$ Entrevista realizada em dezembro de 2012 com assessora voluntária da FPE.

16 O PLC 122/2006 propõe a criminalização da homofobia. Aprovado na Câmara dos Deputados em 2006, tramitava desde então, no Senado Federal, até ser apensado às reformulações do Código Penal, em dezembro de 2013, após longa batalha travada entre o movimento LGBT e seus opositores católicos e evangélicos. Para aprofundamento dessa discussão, ver Masiero (2013).

17 Exceção feita ao senador Walter Pinheiro (PT-BA) que, de acordo com entrevistas, observações e conversas informais realizadas com parlamentares e assessores durante

Debates do NER, Porto Alegre, ANo I6, N. 27, P. 289-32I, JAN./JUn. 2015 
apensado ao projeto de alteração do Código Penal em dezembro de 2013, o que representou uma grande derrota frente aos parlamentares e lideranças defensoras do movimento LGBT. Estava deflagrado o início do processo que iria culminar com o rompimento de diversos parlamentares religiosos, antes apoiadores de Dilma, com o governo. Foi o caso do Partido Social Cristão que, em abril de 2014, anunciou sua saída da base aliada e o lançamento de candidatura própria ao pleito presidencial de 2014.

\section{MARINA SILVA, PENTECOSTAIS E O MOVIMENTO LGBT NAS ELEIÇŌES PRESIDENCIAIS 2014}

Nesta segunda seção, apresento uma discussão acerca da participação pentecostal nas eleições presidenciais de 2014, especialmente no que se refere ao confronto estabelecido com o movimento LGBT a partir do caso específico da apresentação e alteração do programa da candidata Marina Silva e suas repercussóes junto às lideranças pentecostais e ao movimento LGBT.

O pleito presidencial de 2014 contou com onze candidatos, aglutinando coligações com 32 partidos políticos. A candidatura de Dilma Rousseff apresentou a coligação Com a Força do Povo, composta por nove partidos: PT, PMDB, PSD, PP, PR, PDT, PRB, PROS e PCdoB. O PSDB lançou Aécio Neves através da coligação $M u d a$ Brasil, agregando, além do próprio PSBD, também os partidos SD, PMN, PEN, PTN, PTC, DEM, PTdoB e PTB. O PSB havia inicialmente lançado o ex-governador de Pernambuco e ex-aliado político do governo petista, Eduardo Campos como candidato pela coligação Unidos pelo Brasil, juntamente com os partidos PSB, PPS, PSL, PHS, PPL e PRP. A ex-presidenciável Marina Silva, após ter o registro do seu partido - Rede Sustentabilidade - negado pelo Tribunal Superior Eleitoral, ficou assim impossibilitada de concorrer à presidência em 2014

trabalho de campo no Congresso Nacional em dezembro de 2013, foi peça importante para o desfecho favorável aos religiosos opositores do projeto.

Debates do NER, Porto Alegre, ano I6, N. 27, P. 289-32I, JAn./Jun. 2015 
por esta sigla. Filiada, então, ao PSB, acabou candidata à vice-presidência na chapa de Eduardo Campos. Com a morte trágica de Campos, poucos dias antes do início da propaganda eleitoral gratuita, Marina foi alçada presidenciável pela chapa. Os demais candidatos disputaram o pleito sem coligaçôes com outros partidos: Pastor Everaldo, pelo PSC; Luciana Genro, pelo PSOL; Eduardo Jorge, pelo PV; Levy Fidelix, pelo PRTB; José Maria Eymael, pelo PSDC; José Maria de Almeida, pelo PSTU; Mauro Luis Iasi, pelo PCB, e Rui Costa Pimenta, pelo PCO.

A campanha presidencial de 2014 foi a primeira na história brasileira a contar com a participação de dois candidatos pentecostais, ambos da Igreja Assembleia de Deus. É importante destacar, no entanto, que essa característica por si só não significa que as duas candidaturas sejam igualmente definidas como "pentecostais" ou mesmo "evangélicas". Pelo contrário. No caso em questão, refiro-me às candidaturas de Marina Silva (PSB) e de Pastor Everaldo (PSC). Enquanto o último definiu-se desde o início como candidato evangélico, adotando como slogan principal a defesa da família tradicional, Marina Silva, embora fiel da igreja pentecostal, tem marcado sua trajetória política pela defesa do estado laico e da separação entre política e religião.

Além disso, Marina Silva é ambientalista e possui uma trajetória política de esquerda. Boa parte dos seus eleitores não é evangélica, mas busca uma opção à tradicional polarização entre os partidos PT e PSDB que tem caracterizado as eleiçôes presidenciais brasileiras desde 1994. No pleito de 2010, concorrendo sob a sigla do Partido Verde (PV), Marina Silva alcançou o terceiro lugar, com 20 milhões de votos, sustentando o discurso em defesa do estado laico e da separação entre as esferas política e religiosa. Embora pessoalmente contra o aborto (cuja descriminalização ou não era lançada como pauta aos candidatos), defendeu a realização de um plebiscito junto à sociedade ao invés de se posicionar contra a prática, conforme desejo manifesto de muitas lideranças religiosas. Por conta disso, perdeu apoio de lideranças evangélicas como o Pastor Silas Malafaia, que passou a orientar o voto de seus fiéis para o candidato José Serra (PSDB). Apesar disso, de 
acordo com diversas pesquisas eleitorais, muitos fiéis votaram e votam em Marina, o que explica a contínua cobrança sobre Marina por parte das lideranças pentecostais que exigem seu posicionamento alinhado com os interesses do segmento, especialmente no que se refere a questóes como aborto e casamento homoafetivo.

Em 2014, após ter a tentativa de formação de seu partido (REDE Sustentabilidade) frustrada, Marina acabou filiando-se ao PSB e compondo candidatura à presidência na condição de vice, ao lado do governador de Pernambuco, Eduardo Campos. Tornou-se presidenciável a partir do acidente que vitimou Campos, em agosto, a poucos dias do início da campanha eleitoral.

Em determinado momento da campanha eleitoral presidencial de 2014, Marina Silva lançou seu programa de governo, o qual trouxe diversas proposiçôes alinhadas com as reivindicações do movimento LGBT, entre as quais o casamento civil homoafetivo e a adoção de crianças por casais do mesmo sexo. Imediatamente, Silas Malafaia, uma importante liderança pentecostal brasileira, reagiu e exigiu a alteração do programa através de sua conta pessoal na rede social Twitter. No dia seguinte, a coordenação de campanha de Marina retificou o programa, alegando erro na divulgação. Independentemente da motivação que levou a candidata a realizar a alteração programática, o caso foi emblemático para demonstrar o embate político entre lideranças pentecostais e aquelas em defesa dos direitos LGBT no cenário político brasileiro, como será argumentado no decorrer desta seção.

Ainda que tal sentimento não tenha se expressado nas urnas, com a repentina candidatura de Marina em 2014, parte das lideranças evangélicas, que via na candidatura do Pastor Everaldo uma real possibilidade de fortalecimento político do segmento evangélico, começou a ver seu projeto desmoronar.

O Pastor Everaldo e seu partido, PSC, em 2010, haviam apoiado a candidata Dilma Rousseff, compondo parte do que Oro e Mariano (2010) definiram como a "tropa de choque" de deputados e senadores evangélicos, que saiu em defesa de Dilma naquele pleito. No entanto, eventos como

Debates do NER, Porto Alegre, ano I6, N. 27, P. 289-32I, JAn./Jun. 2015 
o silêncio diante dos protestos que cercaram a indicação do Pastor Marco Feliciano (PSC-SP) para a Comissão de Direitos Humanos e Minorias da Câmara dos Deputados em 2013, bem como outras ações oriundas especialmente do Ministério da Saúde e do Ministério da Educação ${ }^{18}$ foram interpretadas por esse grupo como se Dilma estivesse descumprindo seu acordo e o partido, até então da base governista, rompeu com o governo no início de 2014 e lançou a candidatura do Pastor Everaldo (PSC). Se, em 2010, o debate em torno das possíveis políticas para o aborto mobilizou as lideranças evangélicas, em 2014, a temática preponderante foi a questão da criminalização da homofobia e o casamento homoafetivo, colocando em lados opostos, lideranças pentecostais e movimento LGBT.

$\mathrm{Na}$ primeira pesquisa realizada pelo Datafolha após o registro oficial das candidaturas, nos dias 15 e 16 de julho de 2014, a candidata à reeleição Dilma Rousseff (PT) alcançou 36\% das intençôes de voto. O candidato do PSDB, Aécio Neves apresentou 20\% e Eduardo Campos (PSB), 8\% das intenções de voto. Pesquisa realizada um mês depois, após o cenário eleitoral mudar drasticamente em razão da trágica morte do candidato Eduardo Campos e a provável substituição de sua candidatura por Marina Silva, demonstra que Dilma e Aécio permaneciam com a mesma preferência eleitoral: $36 \%$ para Dilma e $20 \%$ para Aécio. A candidatura do PSB, no entanto, salta dos 8\% de Eduardo Campos, para 21\% com Marina Silva, retirando votos sobretudo de indecisos, do Pastor Everaldo e de antipetistas. É o primeiro indício de que os eleitores evangélicos podem estar migrando

\footnotetext{
${ }^{18}$ Entrevistas realizadas com assessores e parlamentares evangélicos identificaram um grande descontentamento com relação a ações dos Ministérios da Saúde e Educação. Como exemplo, o caso das cartilhas do Ministério da Saúde acerca dos Programas de redução de danos que, no entendimento desses parlamentares e seus assessores, estaria estimulando as crianças e os adolescentes a consumirem drogas. No caso do Ministério da Educação, os exemplos referem-se à distribuição de livros didáticos que apresentem em suas histórias famílias homoafetivas o que, na sua perspectiva, incentivaria as crianças e os adolescentes a se tornarem homossexuais.
}

Debates do NER, Porto Alegre, ANo I6, N. 27, P. 289-32I, JAN./JUn. 2015 
ou decidindo seus votos em favor de Marina, que poderia estar aglutinando também, uma legião de insatisfeitos que veriam nela sua representação e chance de mudança. A pesquisa do Datafolha detalha ainda as intenções de voto por religião, de modo que a candidatura de Marina tem a simpatia de $24 \%$ dos evangélicos pentecostais, $27 \%$ dos não pentecostais e apenas $19 \%$ dos católicos. Já Dilma, tem 39\% das intenções de voto entre os católicos, $32 \%$ entre os pentecostais e 30\% entre evangélicos não pentecostais.

Os dados da tabela a seguir, elaborada a partir de pesquisas realizadas pelo Instituto Datafolha, apresenta os percentuais de intenção de voto em Marina Silva em quatro datas diferentes: em 18 de agosto, após a morte de Eduardo Campos e dois dias antes da candidatura de Marina ser oficializada pelo PSB em seu lugar; em 29 de agosto, data da divulgação do seu polêmico plano de governo, caso que será explanado a seguir; em 03 de setembro, momento posterior às polêmicas que ocuparam o debate eleitoral envolvendo as críticas religiosas ao caráter progressista de suas proposições para o segmento LGBT lançadas em 29/08, a posterior retificação do programa e as consequentes críticas do movimento LGBT em razão da alteração e; em 02 de outubro, às vésperas do $1^{\circ}$ turno do pleito eleitoral. Interessante notar os percentuais de intenção de voto em Marina Silva mais elevados entre os evangélicos não pentecostais do que entre os pentecostais. O que mais chama a atenção nos dados, no entanto, é o fato de suas intenções de voto não terem sofrido alterações no curto prazo em razão das polêmicas em torno da alteração do programa de governo da candidata, nem entre os eleitores de modo geral, nem entre os evangélicos. A queda nas intenções de voto demonstrada às vésperas da eleição, que culminou com sua derrota no primeiro turno das eleições, ainda que possa ter respingos das controvérsias geradas a partir da referida alteração de programa, explica-se mais pelas contradições políticas da candidata Marina do que por sua identidade religiosa. 
Tabela 1 - Intenção de voto em Marina Silva (PSB)

\begin{tabular}{c|c|c|c|c}
\hline Religião & $\mathbf{1 8 / a g o}$ & $\mathbf{2 9 / a g o}$ & $\mathbf{0 3 / s e t}$ & $\mathbf{0 2 / \text { out }}$ \\
\hline Geral & $21 \%$ & $34 \%$ & $34 \%$ & $24 \%$ \\
\hline Evangélico não pentecostal & $27 \%$ & $44 \%$ & $45 \%$ & $36 \%$ \\
\hline Evangélico Pentecostal & $24 \%$ & $41 \%$ & $39 \%$ & $34 \%$ \\
\hline
\end{tabular}

Fonte: Instituto de pesquisas Datafolha.

Ainda que Marina Silva buscasse marcar seus discursos pela separação entre religião e política e a defesa do estado laico, sua entrada na disputa presidencial reforçou o tema da religião na campanha eleitoral de 2014. Tão logo o Partido Socialista Brasileiro (PSB) anunciou a decisão de ter Marina como candidata, ao lado de Beto Albuquerque como vice, a imprensa ${ }^{19}$ já tratou de anunciar que a evangélica ${ }^{20}$ Marina teria como vice um defensor da causa homossexual e do aborto. Além disso, seu discurso de mudança e rejeição à velha politica foi imediatamente comparado ao de Fernando Collor de Mello em 198921. O colunista do Estadão, Dener Giovanini, afirmou em seu blog, logo após a indicação da candidatura de Marina que ela estaria necessariamente "fadada a trair" ${ }^{22}$, ou os movimentos sociais, ou os evangélicos, numa clara afirmação de que suas tentativas de agradar a todos não se sustentariam por muito tempo.

O maior impacto da entrada de Marina na disputa, no entanto, foi justamente entre os evangélicos. O PSC e diversas lideranças evangélicas

${ }^{19}$ Disponível em: <http://www.revoltabrasil.com.br/politica/4774-evangelica-marina-teracomo-vice-defensor-da-causa-homossexual-e-do-aborto.html>. Acesso em: 21 ago. 2014.

${ }^{20}$ Cabe salientar a tentativa da mídia de enquadrar Marina como uma candidata evangélica, por um lado, e, por outro, seu esforço constante de desvincular-se de tal rótulo.

${ }^{21}$ Disponível em: <http://www1.folha.uol.com.br/poder/2014/08/1503707-analiserompimento-em-chapa-de-marina-e-lembrete-da-realidade.shtml>. Acesso em: 21 ago. 2014.

22 Disponível em: <http://sustentabilidade.estadao.com.br/blogs/dener-giovanini/as-traicoes-de-marina-bem-que-avisei/>. Acesso em: 20 ago. 2014.

Debates do NER, Porto Alegre, Ano i6, N. 27, P. 289-32I, JAN./Jun. 2015 
apostavam na candidatura do Pastor Everaldo como forma de fortalecer o segmento evangélico no cenário político naciona ${ }^{23}$. A candidatura de Marina, para eles, poderia promover o chamado "voto útil" dos evangélicos, já que Marina apresentava chances reais de disputar o segundo turno e até vencer o pleito ${ }^{24}$, o que enfraqueceria a candidatura do Pastor Everaldo. Ainda em agosto, pesquisas de intenção de voto demonstraram a força da candidatura de Marina Silva. Seja por comoção oriunda da tragédia que se abateu sobre Eduardo Campos, pela fidelização de seus eleitores de 2010, que, de acordo com algumas análises, estariam agora saindo do rol dos indecisos para apoiá-la, ou pelo voto útil dos evangélicos, o fato é que as pesquisas apontavam crescimento da sua candidatura. Pesquisa do Ibope divulgada em 26 de agosto mostrou a candidata com $29 \%$ das intenções de voto e Dilma com 34\%. Nesse cenário, Marina venceria a disputa no segundo turno por $45 \%$ dos votos contra $36 \%$ de Dilma. A hipótese do voto útil, não somente evangélico, mas também do antipetismo, se fortalece, uma vez que de acordo com essa projeção, somente Marina conseguiria vencer Dilma no segundo turno. Conforme essa pesquisa, Aécio Neves perderia a disputa com $35 \%$ dos votos contra $41 \%$ de Dilma ${ }^{25}$. Pesquisa Datafolha divulgada em 29 de agosto revelou tendência ainda maior de a disputa no segundo turno ocorrer entre as duas candidatas, Dilma e Marina: elas estariam empatadas, cada uma com 34\% das intenções de voto e, no segundo turno, Marina seria eleita com $50 \%$ dos votos contra $40 \%$ de Dilma.

${ }^{23}$ Projeções mais otimistas do partido alcançavam até $10 \%$ dos votos no candidato da Assembleia de Deus no primeiro turno, embora nenhuma pesquisa eleitoral tenha indicado mais do que $3 \%$ das intençôes de voto neste candidato.Ao final do primeiro turno, o candidato recebeu pouco mais de 780 mil votos, o que representa $0,75 \%$ dos votos válidos, amargando a $5^{\text {a }}$ posição no pleito.

${ }^{24}$ Disponível em: <http://www.tribunadabahia.com.br/2014/08/25/marina-silva-deve-a trair-voto-util-de-evangelicos>. Acesso em: 27 ago. 2014.

${ }^{25}$ Disponível em: <http://www1.folha.uol.com.br/poder/2014/08/1506288-com-10-pontos-amais-que-aecio-marina-vence-dilma-em-2-turno-diz-ibope.shtml>. Acesso em: 27 ago. 2014.

Debates do NER, Porto Alegre, ano I6, N. 27, P. 289-32I, JAn./Jun. 2015 
Foi justamente nesse momento da campanha eleitoral que a influência das lideranças religiosas adquiriu maior força e a candidatura de Marina atingiu seu ápice, bem como começou, então, a retroceder nas pesquisas de intenção de voto. Em 29 de agosto, Marina lançou seu programa de governo $^{26}$, prevendo menor presença do Estado na economia e destacando as principais reivindicações dos movimentos LGBT, como a legalização do casamento homossexual, a adoção de crianças por casais do mesmo sexo e a distribuição de material educativo contra a homofobia nas escolas públicas, além do seu comprometimento com a aprovação do projeto de lei de identidade de gênero (a lei João Nery), que regulamenta o direito ao reconhecimento da identidade de gênero das pessoas transexuais. No entanto, a comemoração da comunidade LGBT com relação ao programa divulgado por Marina durou pouco. $\mathrm{O}$ pastor Silas Malafaia foi, senão o primeiro a reagir, o que fez ameaças mais contundentes em sua conta da rede social Twitter:

O programa de governo do partido de Marina é pior que o PT e o PSDB, no que tange aos direitos dos gays. Apoia descaradamente o casamento gay e pede, inclusive, a aprovação do extinto PLC 122, que, entre outras coisas, põe pastor na cadeia. É uma vergonha que prevê casamento, adoção de crianças e etc. Se Marina não se posicionar até segunda, na terça será a mais dura e contundente fala que já dei até hoje sobre um candidato a presidente.

No dia seguinte, sábado (30/8), a coordenação da campanha de Marina Silva divulgou nota, alterando o programa inicialmente apresentado ${ }^{27}$. Alegando "falha processual na editoração" que não "não retrata com fideli-

${ }^{26}$ Disponível em: <http://www1.folha.uol.com.br/poder/2014/08/1508327-confira-oprograma-de-governo-de-marina-silva-ponto-a-ponto.shtml $>;<$ http://politica.estadao. com.br/blogs/roldao-arruda/marina-apoia-principais-reivindicacoes-dos-gays/>. Acesso em: 30 ago. 2014.

${ }^{27}$ Disponível em: <http://www1.folha.uol.com.br/poder/2014/08/1508539-campanhade-marina-elimina-trechos-de-capitulo-lgbt-do-programa.shtml>. Acesso em: 1 set. 2014.

Debates do NER, Porto Alegre, ANo I6, N. 27, P. 289-32I, JAN./Jun. 2015 
dade os resultados do processo de discussão sobre o tema durante as etapas de formulação do plano de governo", a campanha de Marina alterou a redação nas propostas para a comunidade LGBT, eliminando trechos em que a presidenciável se comprometia, se eleita, com a aprovaçáo da lei de identidade de gênero - que permite alteração de nome e sexo na documentação - e em articular no Congresso a aprovação de leis que criminalizam a homofobia e regulamentam o casamento gay. Também foi excluída parte que previa a distribuição de material didático "destinado a conscientizar sobre a diversidade de orientação sexual e às novas formas de família”. A coordenação ainda afirmou que a divulgação do programa anterior consistiu em um "contratempo indesejável" com "alguns equívocos" e que o novo seria o "correto". A introdução do capítulo do programa também sofreu alteração. Inicialmente, dizia que

Vivemos em uma sociedade sexista, heteronormativa e excludente em relação às diferenças em que os direitos humanos e a dignidade das pessoas são constantemente violados e guiados, sobretudo, pela cultura hegemônica de grupos majoritários (brancos, homens etc). [...] precisamos superar o fundamentalismo incrustado no Legislativo e nos diversos aparelhos estatais, que condenam o processo de reconhecimento dos direitos LGBT e interferem nele. ${ }^{28}$

O novo programa inicia dizendo que

Vivemos em uma sociedade que tem muita dificuldade de lidar com as diferenças de visão de mundo, de forma de viver e de escolhas feitas em cada área da vida. [...] a democracia só avança se superar a forma tradicional de supremacia da maioria sobre a minoria e passar a buscar que todos tenham formas dignas de se expressar e ter atendidos seus interesses. Os grupos LGBT estão entre essas minorias que têm direitos civis que precisam ser respeitados, defendidos e reconhecidos, pois a Constituição Federal diz que todos são iguais perante a lei, independentemente de idade, sexo, raça, classe

${ }^{28}$ Disponível em: <http://www1.folha.uol.com.br/poder/2014/08/1508539-campanhade-marina-elimina-trechos-de-capitulo-lgbt-do-programa.shtml>. Acesso em: 1 set. 2014.

Debates do NER, Porto Alegre, ano I6, N. 27, P. 289-32I, JAn./Jun. 2015 
social. Assim como em relação às mulheres, aos idosos e às crianças, algumas políticas públicas precisam ser desenvolvidas para atender a especificidade das populações LGBT $^{29}$.

Para o movimento LGBT, as alteraçōes caracterizaram uma forte recuada diante da pressão evangélica. $\mathrm{O}$ plano inicialmente divulgado afirmava que o governo de Marina apoiaria propostas em defesa do casamento civil igualitário. O trecho recebeu nova redação prometendo "[...] garantir os direitos oriundos da união civil entre pessoas do mesmo sexo". O tópico que mencionava a articulação da votação do PLC 122/2006, equiparando a discriminação por orientação sexual às leis existentes para discriminação em razão de cor, etnia, nacionalidade e religião, foi excluído.

Com o recuo e as modificações, o pastor Silas Malafaia garantiu que no segundo turno seu voto iria para Marina Silva, mas não se deu totalmente por satisfeito e aproveitou para acusar o movimento LGBT de intolerante:

[...] os direitos para os gays lá [no programa de Marina] ainda estão grandes e eu não concordo com eles. $\mathrm{O}$ programa dela não tem nenhuma linha do pensamento cristão mas tem dez para os gays. Os intolerantes são eles. Quem não quer dialogar são eles [os ativistas gays]. ${ }^{30}$

O deputado federal Jean Wyllys (PSOL-RJ), homossexual e defensor das conquistas LGBT, rapidamente reagiu ao recuo de Marina e afirmou, tanto em sua conta pessoal na rede social Facebook como em coluna da revista Carta Capital, na data de 30 de agosto:

Bastaram quatro tuites do pastor Malafaia para que, em apenas 24 horas, a candidata se esquecesse dos compromissos de ontem, anunciados em um ato público transmitido por televisão, e desmentisse seu próprio programa de governo, impresso em cores e divulgado pelas redes. Marina também retirou

${ }^{29}$ Disponível em: <http://marinasilva.org.br/programa/\#!/>. Acesso em: 2 set. 2014.

${ }^{30}$ Disponível em: <http://oglobo.globo.com/brasil/dilma-o-pt-acham-que-pastor-otarioevangelico-idiota-diz-silas-malafaia-13806542\#ixzz3QcWMtvyb>. Acesso em: 3 set. 2014.

Debates do NER, Porto Alegre, Ano i6, N. 27, P. 289-32I, JAN./Jun. 2015 
do programa o compromisso com a aprovação da lei João Nery, a elaboração de materiais didáticos sobre diversidade sexual, a criminalização da homofobia e da transfobia e outras propostas. Só deixou frases bonitas, mas deletou todas as propostas realmente importantes. E ela ainda nem se elegeu! O que esperar então dela se eleita presidenta quando a bancada fundamentalista, a bancada ruralista e outros grupos de pressão começarem a condicionar o apoio a seu governo? Tem políticos que renunciam a seus compromissos de campanha e descumprem suas promessas depois de eleitos. Marina já fez isso mais de um mês antes do primeiro turno. Que medo! [...] Ontem, quando consultado pela imprensa, apesar da minha desconfiança com relação à Marina, elogiei o programa apresentado pelo PSB [...] no que dizia respeito aos direitos da população LGBT. [...] É com essa autoridade, de quem agiu de boa fé, que agora digo: Marina, você não merece a confiança do povo brasileiro! Você mentiu a todos nós e brincou com a esperança de milhões de pessoas. ${ }^{31}$

A polêmica em torno dessa mudança de programa de Marina Silva, além das reações negativas no movimento LGBT e positivas diante das lideranças evangélicas, provocou também uma reação na campanha à reeleição de Dilma. Logo após o final do debate realizado no SBT entre os presidenciáveis, na segunda-feira, 01/09, em entrevista a jornalistas, a presidenta acenou com apoio ao projeto de criminalização da homofobia:

Fico muito triste de ver que nós temos hoje grandes índices de violência atingindo essa população, principalmente quando se trata de homossexuais, mas também em todas as outras áreas. Acho que a gente tem de criminalizar a homofobia. O que eu estou dizendo é que se deve criminalizar a homofobia. A homofobia não é algo que a gente possa conviver ${ }^{32}$.

${ }^{31}$ Disponível em: <http://www.cartacapital.com.br/politica/direitos-lgbt-marina-voce -brincou-com-a-esperanca-de-milhoes-de-pessoas-6905.html>. Acesso em: 1 set. 2014.

32 Disponível em: <http://jornalggn.com.br/blog/gunter-zibell-sp/dilma-roussef-dizque-homofobia-deve-ser-criminalizada>. Acesso em: 2 set. 2014.

Debates do NER, Porto Alegre, ano I6, N. 27, P. 289-32I, JAn./Jun. 2015 
Apesar dessa manifestação de apoio, o fato de o PLC 122/2006 ter ficado parado no Senado durante todo o seu mandato, sem nenhuma manifestação sua favorável à aprovação, causou desconfiança no movimento LGBT e nos parlamentares que o defendem. O pastor Silas Malafaia aproveitou para chamar a presidenta de hipócrita ao acenar com apoio a igrejas evangélicas:

Em época de eleição, a hipocrisia e o desespero correm solto. [...] Nós lutamos sete anos, de maneira legal e democrática para enterrar o PLC 122, aquele famigerado projeto de lei para beneficiar o ativismo gay. E agora, Dilma, no desespero por causa de Marina, diz que vai apoiar e que apoia a criminalização da homofobia, quer dizer, ela apoia a volta do PLC 122, que foi derrotado pela via democrática ano passado no Senado. A gente já sabe que o PT só procura os evangélicos de quatro em quatro anos, no restante do tempo trabalha contra tudo aquilo que é relativo às nossas crenças e valores. Agora a hipocrisia legal é o seguinte que no mesmo desespero para agradar o ativismo gay e ela diz que vai apoiar a criminalização da homofobia, ela também acena que vai apoiar as igrejas evangélicas. Ah, não, isso aí não. Esse é um atentado à nossa inteligência. [...] Olha, manda um lustra móveis para a Dilma, a cara de pau. ${ }^{33}$

Evidencia-se, aqui, novamente, a tentativa de acomodação das demandas conflitantes. Se, em 2010, Dilma buscou acomodar as lideranças pentecostais ao assinar a "fatura" por eles apresentada, em 2014, o esforço aparece para acomodar o movimento LGBT com o aceno da criminalização da homofobia.

Diante desse cenário e de fortes possibilidades de virem a se enfrentar no segundo turno da disputa, as candidatas Dilma e Marina passaram a trocar ataques, também sobre esse tema. Logo após o debate presidencial promovido pela Folha de São Paulo, UOL, SBT e Jovem Pan, na segunda-feira (1/9), a presidenta Dilma Rousseff afirmou que o recuo da ex-senadora era "uma

${ }^{33}$ Disponível em: <http://noticias.gospelprime.com.br/video-silas-malafaia-x-dilmarousseff/>. Acesso em: 3 set. 2014.

Debates do NER, Porto Alegre, ANo I6, N. 27, P. 289-32I, JAN./Jun. 2015 
ofensa para o Brasil" e prometeu defender a criminalização da homofobia. Marina retrucou atacando o programa do PT, o que para ela "só não ganha em conservadorismo do programa do Pastor Everaldo" ${ }^{34}$.

Dois dias depois, em nova coluna na revista Carta Capital, Jean Wyllys volta ao assunto, dessa vez, dirigindo-se à candidata à reeleição Dilma Rousseff que, na avaliação do parlamentar, está agora dedicando uma importância à temática LGBT não manifesta durante seu mandato, e afirma:

Eu reconheço, contudo, uma diferença entre a senhora, presidenta Dilma, e a candidata Marina. Seu governo cede ao fundamentalismo como parte de uma concepção nada democrática e covarde de 'governabilidade', que a leva a ceder também aos abusos dos ruralistas, banqueiros e outras corporações. E imagino que, muitas vezes, a senhora faça isso com muita dor, até pessoal - mas, mesmo assim, faz! Já a Marina cede não só em função do cálculo eleitoral (e, em última instância, da 'governabilidade'), mas por estar submissa aos dogmas fundamentalistas que estruturam sua visão de mundo. Ela, portanto, oferece mais riscos aos direitos das minorias religiosas e sexuais (a comunidade LGBT). E não pode mudar; não vai mudar. ${ }^{35}$

Nesse contexto de embates, a campanha prossegue com as lideranças evangélicas dividindo-se no que diz respeito ao apoio às candidaturas de Marina Silva (PSB) e Pastor Everaldo (PSC). Pastor Everaldo marca sua candidatura como aquela defensora dos valores cristãos e da família tradicional, e Marina busca afirmar-se como a candidata da "nova política" que, apesar de evangélica, separa suas crenças pessoais de sua atuação política. Menos por sua identidade religiosa e mais por suas contradições políticas, o discurso de Marina não se sustenta e a candidata perde força, repetindo, ao final do primeiro turno, o desempenho eleitoral de 2010, quando amargou a $3^{\text {a }}$ colocação com pouco mais de 20 mil votos.

\footnotetext{
${ }^{34}$ Disponível em: idem.

${ }^{35}$ Disponível em: <http://www.cartacapital.com.br/politica/sim-dilma-nos-podemos-6116. html?utm_content=buffera8b40\&utm_medium=social \&utm_source=twitter.com\&utm_ campaign=buffer $>$. Acesso em: 3 set. 2014. Grifo do autor.
}

Debates do NER, Porto Alegre, ano I6, N. 27, P. 289-32I, JAn./Jun. 2015 
Na verdade, depois do presidente Luís Inácio Lula da Silva tentar agradar os dois lados desse embate desde sua primeira gestão, e sua sucessora, Dilma Rousseff, seguir tentando, o que se verifica na atualidade é uma disputa, no meio político, entre a reivindicação pentecostal para um maior controle social por parte do estado na área dos costumes (argumento religioso), e a reivindicação dos movimentos feminista e LGBT por autonomia e direitos civis (argumento laico). Trata-se da disputa entre o controle social, no sentido de que as lideranças pentecostais almejam controlar os costumes ${ }^{36}$, para que todas as famílias brasileiras se encaixem na sua composição tradicional (a partir da união entre um homem e uma mulher), restringindo assim os direitos civis dos casais homoafetivos, em contraposição ao direito à autonomia individual, reivindicado pelos movimentos sociais, em especial as lideranças LGBT (mas também as feministas) no sentido de usufruir dos mesmos direitos civis de escolha de sua composição familiar. O projeto 6583/2013, de autoria do deputado federal evangélico Anderson Ferreira (PR-PE), que propõe a instituição do Estatuto da Família, ilustra bem tal embate. Segundo o artigo $2^{\circ}$ da proposição ${ }^{37}$, a entidade familiar passaria a ser definida como

[...] o núcleo social formado a partir da união entre um homem e uma mulher, por meio de casamento ou união estável, ou ainda por comunidade formada por qualquer dos pais e seus descendentes.

O projeto gerou inúmeros debates no interior do Congresso Nacional e mobilizou tanto a comunidade LGBT como os evangélicos em uma enquete ${ }^{38}$

\footnotetext{
${ }^{36} \mathrm{O}$ desejo dos pentecostais pelo controle social estatal na área dos costumes não se limita à definição de família enquanto aquela constituída somente pela união entre um homem e uma mulher, mas expande-se para outras esferas como as políticas de saúde e educação.

37 Disponível em: <http://www.camara.gov.br/proposicoesWeb/prop_mostrarintegra? codteor $=1159761 \&$ filename=PL+6583/2013>. Acesso em: 23 abr. 2014.

38 Disponível em: <http://www2.camara.leg.br/camaranoticias/noticias/DIREITOS -HUMANOS/462211-ENQUETE-SOBRE-ESTATUTO-DA-FAMILIA-BATERECORDE-DE-ACESSOS-AO-SITE-DA-CAMARA.html>. Acesso em: 23 abr. 2014.
}

Debates do NER, Porto Alegre, ANo I6, N. 27, P. 289-32I, JAN./Jun. 2015 
que bateu recordes de acessos no site da Câmara Federal durante o ano de $2014^{39}$. Toda essa controvérsia invadiu o cenário eleitoral de 2014, colocando pentecostais e LGBT em lados opostos, o que pode ser verificado tanto através do Pastor Everaldo e seus discursos em defesa da família tradicional como através do caso da apresentação e posterior alteração do programa de Marina Silva no que se refere à garantia dos direitos LGBT.

A disputa entre Dilma Rousseff (PT) e Aécio Neves (PSDB) no segundo turno da eleição foi a mais acirrada de toda a história do Brasil desde a redemocratização do país. No entanto, diferentemente de 2010, em que os temas do aborto e dos direitos civis de homossexuais pautaram diversos momentos importantes da campanha, o segundo turno do pleito de 2014 trouxe à tona muito mais uma luta ideológica de classes, em que o maior objetivo dos adversários de Dilma, religiosos ou não, era derrotar o programa petista e evitar uma nova vitória do Partido dos Trabalhadores. Nesse cenário, ainda que houvesse comitês evangélicos apoiando Dilma e lideranças LGBT defendendo Aécio, em grande medida o segmento pentecostal que havia apoiado Dilma em 2010 colocou-se contra sua reeleição e ficou ao lado da direita pró-Aécio. Da mesma forma, boa parte do movimento e das lideranças LGBT postou-se à esquerda, apoiando Dilma, em um claro posicionamento na luta de classes que polarizou as eleiçôes presidenciais de 2014.

\footnotetext{
${ }^{39}$ Há ainda dois outros projetos em tramitação no Congresso Nacional, ambos defendidos pelo movimento LGBT que almejam regulamentar acerca da constituição familiar. O primeiro é o projeto 2285/2007, de autoria do deputado federal Sergio Barradas Carneiro (PT/BA) e apensado ao PL 674/2007, de autoria do Deputado Candido Vacareza (PT/ $\mathrm{SP})$, que versa sobre união estável e propõe o Estatuto das Famílias, reconhecendo a diversidade dessa instituição. O segundo é o projeto 470/2013, de autoria da Senadora Lídice da Mata (PT/BA). Ambos são alvos de críticas da Frente Parlamentar Evangélica, que defende a proposição do deputado Anderson Ferreira. (Disponível em: <http://www. fpebrasil.com.br/portal/index.php/noticias/121-conhecam-os-estatutos-da-familia>. Acesso em: 6 dez. 2014.) Esse debate, no entanto, não será foco da análise desse artigo.
}

Debates do NER, Porto Alegre, ano I6, N. 27, P. 289-32I, JAn./Jun. 2015 


\section{CONSIDERAÇÕES FINAIS}

O presente artigo realizou uma análise da disputa entre a atuação do segmento pentecostal e o movimento LGBT que se manifestou na campanha eleitoral presidencial de 2014. Com o intuito de compreender o processo que culminou em 2014, busquei mapear, na primeira parte deste artigo, o processo político pelo qual lideranças evangélicas foram ganhando espaço e força política, bem como colocando-se em confronto com movimentos sociais, especialmente feministas e LGBT na tentativa de estancar a conquista de direitos sociais que esses movimentos vêm alcançando.

$\mathrm{Na}$ segunda parte do texto, detive-me no primeiro turno das eleições presidenciais de 2014. Explorei especialmente o caso da controversa alteração no programa de Marina Silva sobre as políticas para o segmento LGBT. Independentemente da motivação que levou a candidata a realizar a alteração programática, o caso foi emblemático para demonstrar o embate político entre lideranças pentecostais e lideranças em defesa dos direitos LGBT.

Se, em gestôes anteriores, os governos Lula e Dilma, de alguma forma, conseguiram acomodar as diferentes demandas do movimento LGBT e segmento pentecostal, a tentativa de Marina no cenário eleitoral de 2014 não teve a mesma eficácia. Com o empoderamento conquistado após décadas de lutas no campo político democrático, ambos os movimentos alcançaram legitimidade junto a suas bases e parte da sociedade para reivindicar suas conquistas. $\mathrm{O}$ caso exposto na campanha presidencial de 2014 evidenciou a dificuldade de se acomodar demandas opostas quando a reivindicação de um segmento social exige a não concessão do direito reclamado pelo outro. 


\section{REFERENNCIAS}

BAPTISTA, Saulo. Pentecostais e neopentecostais na politica brasileira: um estudo sobre cultura política, Estado e atores coletivos religiosos no Brasil. São Paulo: Annablume; São Bernardo do Campo: Instituto Metodista Izabela Hendrix, 2009.

BEAMAN, Lori. Reasonable accommodation: managing religious diversity. Vancouver: UBC Press, 2012.

BOHN, Simone. Evangélicos no Brasil: Perfil socioeconômico, afinidades ideológicas e determinantes do comportamento eleitoral. Opiniāo pública, Campinas, v. X, n. 2, p. 288-338, out. 2004.

Contexto político-eleitoral, minorias religiosas e voto em pleitos eleitorais. Opinião pública, Campinas, v. 13, n. 2, p. 366-387, nov. 2007.

BURITY, Joanildo. Identidade e política no campo religioso. Recife: IPESPE/ Editora Universitária/EFPE, 1997.

DUARTE, Tatiane dos Santos. "A casa dos impios se desfará, mas a tenda dos retos florescerá": a participação da Frente Parlamentar Evangélica no legislativo brasileiro. 2011. Dissertação (Mestrado em Antropologia Social) - Universidade de Brasília, Brasília, DF, 2011.

FONTES, Maria Lucineide Andrade. O enquadramento do aborto na mídia impressa brasileira nas eleições 2010: a exclusão da saúde pública do debate. Ciência \& Saúde Coletiva, Rio de Janeiro, v. 17, n. 7, p. 1805-1812, 2012.

FRESTON, Paul. Protestantes e politica no Brasil: da Constituinte ao Impeachment. 1993. Tese (Doutorado em Sociologia)-Departamento de Ciências Sociais no Instituto de Filosofia e Ciências Humanas da Universidade de Campinas, Campinas, 1993.

Debates do NER, Porto Alegre, ano I6, N. 27, P. 289-32I, JAn./Jun. 2015 
MACHADO, Maria das Dores Campos. Aborto e ativismo religioso nas eleiçōes de 2010. Revista Brasileira de Ciência Política, Brasília, DF, n. 7, p. 25-54, jan./abr. 2012a.

Religião, Cultura e Política. Religião e Sociedade, Rio de Janeiro, v. 32, n. 2, p. 29-56, 2012b.

MARIANO, Ricardo. A reação dos evangélicos ao novo Código Civil. Revista Civitas, Porto Alegre, v. 6, n. 2, p. 77-99, jul./dez. 2006.

Pentecostais e política no Brasil: do apolitismo ao ativismo corporativista. In: SANTOS, Hermílio (Org.). Debates pertinentes: para entender a sociedade contemporânea [online]. v. 1. Porto Alegre: EDIPUCRS, 2009.

MARIANO, Ricardo; PIERUCCI, Antônio Flávio. O envolvimento dos pentecostais na eleição de Collor. In: PIERUCCI, Antônio Flávio; PRANDI, Reginaldo. A realidade social das religiōes no Brasil. São Paulo: Ed. Hucitec, 1996

MARIANO, Ricardo; HOFF, Márcio; DANTAS, Toty Ypiranga de Souza. Evangélicos sanguessugas, presidenciáveis e candidatos gaúchos: a disputa pelo voto dos grupos religiosos. Debates do NER. Porto Alegre, ano 7, n. 10, p. 65-78, jul./dez. 2006.

MARSIAJ, Juan. Social movements and political parties: gays, lesbians, and travestis and the struggle for inclusion in Brazil. Canadian Journal of Latin American and Caribbean Studies, Toronto, v. 31, n. 62, p. 167-196, 2006.

MASIERO, Clara. Criminalização da homofobia e política-criminal brasileira: Análise-crítica do PLC 122/2006. Sistema Penal \& Violência, Porto Alegre, v. 5, n. 2, p. 171-186, jul./dez. 2013.

ORO, Ari; MARIANO, Ricardo. Eleições 2010: religião e política no Rio Grande do Sul. Debates do NER, Porto Alegre, ano 10, n. 16, p. 9-34, 2010. 
PIERUCCI, Antônio Flávio. Representantes de Deus em Brasília: a bancada evangélica na Constituinte. In: PIERUCCI, Antônio Flávio; PRANDI, Reginaldo. A realidade social das religióes no Brasil. São Paulo: Ed. Hucitec, 1996.

Eleição 2010: desmoralização eleitoral do moralismo religioso. Novos Estudos: CEBRAP, São Paulo, n. 89, 2011.

PIERUCCI, Antônio Flávio; PRANDI, Reginaldo. Religiōes e voto: a eleição presidencial de 1994. In: $A$ realidade social das religióes no Brasil. São Paulo: Ed. Hucitec, 1996.

SHIPLEY, Heather. One of these things is not like the other: sexual diversity and accommodation. In: BEAMAN, Lori. Reasonable accommodation: managing religious diversity. Vancouver: UBC Press, 2012.

TADVALD, Marcelo. Eleitos de Deus e pelo povo. Os evangélicos e as eleiçôes federais de 2010. Debates do NER, Porto Alegre, ano 11, n. 18, p. 83-109, jul./dez. 2010.

TREVISAN, Janine. A Frente Parlamentar Evangélica: Força política no estado laico brasileiro. Numen: revista de estudos e pesquisa da religião, Juiz de Fora, v. 16, n. 1, p. 581-609, 2013.

VITAL DA CUNHA, Christina; LOPES, Paulo Victor Leite. Religiāo e política: uma análise da atuação de parlamentares evangélicos sobre direitos das mulheres e LGBTs no Brasil. Rio de Janeiro: Fundação Heinrich Böll Stiftung, 2012.

Recebido em: 03/02/2015

Aprovado em: 15/03/2015

Debates do NER, Porto Alegre, ANo I6, N. 27, P. 289-32I, JAN./Jun. 2015 